\title{
Methodology for assessing the service level offered in the check-in area of brazilian regional airports
}

\author{
Metodologia para estimação do nível de serviço ofertado na área de \\ check-in de aeroportos regionais brasileiros
}

\author{
Bernardo Vilela Mascarenhas ${ }^{1}$, Giovanna Miceli Ronzani Borille ${ }^{2}$, Cláudio Jorge Pinto Alves ${ }^{3}$ \\ ${ }^{1}$ Instituto Tecnológico de Aeronáutica, São Paulo - Brasil, bernardovilelam@gmail.com \\ 2Instituto Tecnológico de Aeronáutica, São Paulo - Brasil, ronzani@ita.com.br \\ 3Instituto Tecnológico de Aeronáutica, São Paulo - Brasil, claudioj@ita.com.br
}

Recebido:

5 de setembro de 2020

Aceito para publicação:

12 de junho de 2020

Publicado:

15 de dezembro de 2020

Editor de área:

Alexandre de Barros

\section{Keywords:}

Airport Terminal.

Level of Service.

Check-in.

\section{Palavras-chaves:}

Terminal de passageiros.

Nível de serviço.

Check-in.

DOI:10.14295/transportes.v28i5.2083

\begin{abstract}
This paper proposes a methodology to evaluate the level of service offered in the checkin area of Brazilian regional airports, using as a case study a passenger terminal project proposed by the National Civil Aviation Secretariat. For this study operational aspects, terminal infrastructure and user profile were considered. The Taguchi Experiment Orthogonal Array Method was used to reduce the number of scenarios evaluated with Queueing Theory. An easy to apply analytical approach to passenger terminal check-in yield results that can assist decision makers in their efforts to reduce investments in the airport construction phase and optimize system operation.
\end{abstract}

\section{RESUMO}

Este trabalho propõe uma metodologia de avaliação do nível de serviço oferecido na área de check-in de aeroportos regionais brasileiros, tendo como estudo de caso um projeto de terminal de passageiros, proposto pela Secretaria Nacional de Aviação Civil. Para o estudo foram considerados aspectos operacionais, de infraestrutura do terminal e perfil dos usuários. O método da matriz de arranjo ortogonal de Taguchi foi utilizado para reduzir a quantidade dos cenários que avaliados pela Teoria de Filas. Uma abordagem analítica e de fácil aplicação para o check-in em terminais de passageiros pode gerar resultados capazes de auxiliar os tomadores de decisão na tentativa de reduzir os investimentos na fase de construção do aeroporto e otimizar a operação do sistema.

\section{INTRODUCTION}

In countries of continental dimensions such as Brazil, the development and integration of their territories are strongly related to regional air transport. The sector plays important roles, among them (i) the provision of services for remote and border regions, as it is the case of the Legal Amazon, (ii) the development of municipalities throughout the national territory, (iii) universal access to air transport, and (iv) the promotion of the tourism industry (Oliveira e Silva, 2008).

The air transport industry in Brazil has developed significantly in recent years, with successive increase in passenger demand. In addition to the country's economic growth, 
efforts to liberalize the market, initiated in the early 1990s, were fundamental to this evolution (McKinsey and Company, 2010).

After more than 10 consecutive years of growth in the Brazilian domestic air transport market, the number of paid passengers transported presented its first reduction in 2016 (7.8\%). Even so, in the same year, a total of 88.7 million passengers were transported only on domestic flights. If added to international flights, the sector recorded an inclusion of 50 million passengers in the last ten years (ANAC, 2017).

According to the National Civil Aviation Secretariat - SAC, Brazilian demand is expected to triple in 20 years, exceeding 600 million passengers per year. Even with this growth in the sector, the Brazilian still travel little by plane, compared to users from developed countries. The Brazilian average is 0.5 air trips per year, against 1.7 in developed countries and 2.5 in the United States (SAC, 2017).

Another characteristic of the Brazilian air network is the high concentration of air traffic in some specific areas. The Southeast Region has the highest density of flights, while large areas, mainly in the North Region, are not served by those airlines. This scenario impedes the social and economic development of the most distant locations and increases social differences in the country. The concentration of flights was also highlighted in the Yearbook of the National Civil Aviation Agency - ANAC in the year 2017. According to the report, of the almost 90 million domestic passengers embarked in Brazil, practically half originated in the southeast region (ANAC, 2017).

The main objective of this study is to develop a methodology to assess the level of service offered in the check-in area of airport terminals, capable of evaluating and predicting the quality of the service offered even at the airport design stage. In addition, it is discussed other important points such as: (i) impact of the passenger profile on the sizing of terminals, (ii) use of new technologies in boarding procedures and (iii) relationship between the checked baggage fee and the required area in the terminal.

\section{LITERATURE REVISION}

This section presents a general approach on the main themes about this study: (i) Passenger terminal at a regional airport, (ii) Service level, (iii) Orthogonal arrangement matrix, (iv) Queuing theory, and (v) Design and evaluation of the operational components of a passenger terminal.

\subsection{The passenger terminal of a regional airport}

The components of a passenger terminal can be divided into two groups according to their functions: operational and non-operational. The operational components are those that interfere with aeronautical activities and are essential in the intermodal transfer process. Non-operational components are those that do not interfere with the operation of the airport, and are used to improve the convenience of its users

The check-in area is one of the operational components and consists basically of the check-in counters, space for serving passengers, space for queuing and a circulation area before the beginning of the queue. Feitosa (2000) defines the space as the "area destined for occupation by users who are being served or waiting in line". 
The considerable increase in the number of passengers and the emergence of new technologies have changed the way which the check-in service is offered and how the capacity of airport passenger terminals is calculated (IATA, 2014). Innovations at airports such as self-service totems for check-in or even devices for the passengers to dispatch their own luggage are increasingly common in Brazilian airports, influencing the way the users behave in relation to the procedures which precede the flight. Therefore, if the airport is equipped with such equipment, it must be considered in the calculation of the airport capacity, as well as its queuing areas.

Before boarding, passengers have the option of processing them in different ways, which may or may not include the use of new technologies such as online check-in or the use of self-service totems at the terminal. The use of these technologies, as well as the need to check baggage, determine the path taken by the passenger immediately after entering the terminal.

\subsection{Level of service}

According to ACRP (2010): "The level of service, in the context of airport terminal planning, is a generic term that describes the service provided qualitatively and quantitatively to airport travelers at various points within the passenger terminal building". In this context, the qualitative approach, or perceived service level, depends on the user's perception and assessment of the passenger terminal related to its facilities and services (Rolim, 2016). The level of service offered quantitatively describes the service of the passenger terminal and is related to the degree of agglomeration or congestion of users and the waiting or processing time. This study deals only with the level of service offered.

The space required for each component of the passenger terminal varies according to the level of service established, which according to IATA (2019) can be subdivided into three categories, being: (i) overestimated, (ii) excellent and (iii) suboptimal. The space available to each user and the estimated waiting time are considered for this classification, being the "overestimated" service level the one which offers the best conditions for the passengers. In previous IATA's studies, the service level was presented on a 6-level scale (from A to F). Table 1 presents the new classification proposed in the tenth edition of the ADRM (Airport Development Reference Manual) - from IATA (2019) and its relationship with the old classification.

Table 1 - Service level parameters proposed by ADRM (IATA, 2019)

\begin{tabular}{cccc}
\hline $\begin{array}{c}\text { IATA classification (from } \\
\text { the ADRM 2014 edition) }\end{array}$ & Space & Time & $\begin{array}{c}\text { IATA classification (prior to } \\
\text { the ADRM 2014 edition) }\end{array}$ \\
\hline Overstimated & Excessive or empty & Supply of excess resources & A, B \\
\hline Excellent & $\begin{array}{c}\text { Enough to accommodate the } \\
\text { necessary functions comfortably }\end{array}$ & $\begin{array}{c}\text { Acceptable processing and } \\
\text { waiting time }\end{array}$ & B, C, D \\
\hline Suboptimal & $\begin{array}{c}\text { Crowded } \\
\text { Uncomfortable }\end{array}$ & $\begin{array}{c}\text { Processing and waiting times } \\
\text { unacceptable }\end{array}$ & D, E, F \\
\hline
\end{tabular}

IATA (2019) also establishes the area of each operational component of the passenger terminal and its processing time, when applicable, so that it offers an adequate level of service to its user. In the case of the check-in area, the processing time also interferes with the service level of this operational component. Table 2 presents the values established by IATA (2019) for the check-in area, as well as the processing time, considering only economy class flights. 
In the case of the level of service offered in the check-in area, the space and time of each level depend on the use of technology by the users. The IATA ADRM manual (2019) considers the use of self-service totems and equipment for baggage clearance by passengers in addition to the traditional counter. As they are regional airports, bag drop dispatch systems will not be considered, as this technology is not part of the reality of small Brazilian airports.

Table 2 - Space and time for check-in procedures and respective service level. Adapted from (IATA, 2019)

\begin{tabular}{|c|c|c|c|c|c|c|c|}
\hline \multirow{3}{*}{\multicolumn{2}{|c|}{ Operational component }} & \multicolumn{3}{|c|}{ Area $\left(\mathrm{m}^{2} / \mathrm{pax}\right)$} & \multicolumn{3}{|c|}{ Processing time (min) } \\
\hline & & \multicolumn{3}{|c|}{ Service level } & \multicolumn{3}{|c|}{$\begin{array}{l}\text { Service level } \\
\end{array}$} \\
\hline & & Over & Excellent & Suboptimal & Over & Excellent & Suboptimal \\
\hline \multirow{3}{*}{ 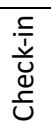 } & Self-service totem & $>1,8$ & $1,3-1,8$ & $<1,3$ & 0 & $0-2$ & $>2$ \\
\hline & Baggage drop-off counter & $>1,8$ & $1,3-1,8$ & $<1,3$ & 0 & $0-5$ & $>5$ \\
\hline & Traditional check-in desk & $>1,8$ & $1,3-1,8$ & $<1,3$ & $<10$ & out/20 & $>20$ \\
\hline
\end{tabular}

\subsection{Orthogonal arrangement matrix}

In this work, a series of experiments was chosen to represent the possible flow of passengers during the procedure to understand the behavior of the queue for checking in at an airport. An experiment, or scenario, is the result of a combination of factors (or parameters) and levels. In this work, the factors are related to the passenger's profile and the airport. The passenger's profile concerns the behavior of the users' arrival, the baggage fee and the type of check-in carried out by the passengers. As for the infrastructure, it is related to the number of counters and self-service totems available.

If the combination of all factors and levels were used, this would require many experiments, making the application of the method unfeasible. Therefore, to reduce the number of tests required, the Orthogonal Array Matrix technique is used The use of matrices with this configuration allows obtaining as much information as possible about the effects of factors with a minimum number of experiments, simplifying the application and analysis of the data (Ross, 1991). The robust project design (Taguchi's Robust Parameter Design - RPD) is an engineering methodology used to improve research productivity and can be developed with single or mixed level orthogonal matrices. Single-level orthogonal matrices are those in which the factors have the same number of levels and are represented as can be seen in Equation (1).

$$
L_{\text {scenarios (levelfactor) }}
$$

The matrices $\mathrm{L}_{9}\left(3^{4}\right)$, L25 (56) and $\mathrm{L}_{32}\left(2^{31}\right)$ are examples of single-level orthogonal matrices. In the orthogonal matrices of mixed level, different factors can have different levels. This is the case of the matrix L'32 $\left(2^{1} \times 4^{9}\right)$ which is formed by a 1 factor with 2 levels and 9 factors with 4 levels each. Examples of mixed matrices are also: (i) L18 $\left(2^{1} \times 3^{7}\right)$, L36 $\left(2^{11} \times 3^{12}\right)$ e L54 $\left(2^{1} \times 3^{25}\right)$. In the standard single-level orthogonal matrix of Taguchi, the number of experiments is represented by letter "L", and it is associated with the number of factors and levels. This relationship is defined by the following Equation 2 (Ross, 1991):

$$
\text { Number of experiments }=1+k(n-1)
$$

\subsection{Queuing theories}

In addition to the Taguchi Method, the Queue Theory method is also used in this work. This method is defined by Fogliatti and Mattos (2007) as an analytical modeling of a system that 
results in waiting. Queues are optimized and evaluated by performance measures, which numerically express the time spent by customers and the average number of users in the system.

According to Arenales (2007), queues can be formed when the demand for a service is greater than its capacity. They can be observed in service systems such as banks, supermarkets, post offices, among others. Queuing theory is the branch of Operations Research that studies the effects of this queue and the relationship among demand for the system, service provision and capacity. Queuing theory can be used to predict the operation of a passenger terminal, for example, and assist in its design and dimensioning of operational components.

\subsubsection{Performance measures}

In queuing theory, a notation is used to describe the type of each queue according to its characteristics and behavior. In this work, the Kendall-Lee notation will be used, which has the following notation (Chwif and Medina, 2014):

$$
(a / b / c):(d / e / f)
$$

Where: (a) represents the distribution of customer arrivals in the system, (b) represents the distribution of system exits (service time), (c) represents the number of system servers, (d) represents queue discipline, (e) represents the maximum number (finite or infinite) allowed in the system, and finally (f) represents the font size of finite or infinite users.

In some studies, the queue representation is simplified and only the first characteristics (a / b / c) are represented. In this research, the rows M / M / k and M / G / k will be used, and their characteristics will be described later.

To describe the arrival of customers in the system, the symbol $\lambda$ is usually used in two ways: (i) number of customers arriving in a certain time interval and (ii) the time between two consecutive arrivals.

The characterization of user service follows the same logic as the arrival of customers in the system and it is represented by $\mu$ in two ways: (i) number of calls in a given time interval (service rate) and (ii) time between two consecutive calls.

In the Theory of Queues, performance indicators are considered to evaluate the operational characteristics, which are calculated for a given model of queues through mathematical correlations. Here are some performance measures relevant to the study and that help to describe and evaluate a queue:

- $\rho:$ Server utilization rate (measures server congestion);

$$
\rho=\frac{\lambda}{\mu k}
$$

- $\mathrm{P}_{0}$ : Probability that the system is idle;

- $P_{n}$ : Probability that there are $n$ customers in the queue or being served;

- L: Average number of customers in the system;

- $\mathrm{L}_{\mathrm{Q}}$ : Average number of customers in the queue;

- W: Average time of the customer in the system; and

- $\mathrm{W}_{\mathrm{Q}}$ : Average time of customer in the queue. 


\subsubsection{Queue of $M / M / k$ type}

In the M / M / k model, k servers are considered, with the arrival of customers in the system $(\lambda)$ and the service time of servers $(\mu)$ following an exponential rate.

After applying equations and mathematical effort, Arenales (2007) defined that the average number of users in the LQ queue can be calculated by the following Equation (3).

$$
L_{Q}=P_{0} \frac{(\rho k)^{k} \rho}{k !(1-\rho)^{2}}
$$

$\mathrm{P}_{0}$ being the probability that the system is empty. Assuming $\rho<0$, the value of P0 is given by the following Equation (4):

$$
P_{0}=\frac{1}{\sum_{n=0}^{k-1} \frac{(k \rho)^{n}}{n !}+\frac{(k \rho)^{k}}{k !(1-\rho)}}
$$

The average time of the customer in the queue (WQ) can be obtained by the relation presented in Equation (5):

$$
W_{Q}=\frac{L_{Q}}{\lambda}
$$

\subsubsection{Queue $M / G / k$ type}

A system is considered M / G / k when only the arrival rate of the customer $(\lambda)$, or passenger, is exponentially distributed. The same does not happen with the service fee $(\mu)$, which has a generic distribution and is considered a standard deviation. In this case the system has less distribution flexibility. More than server $(\mathrm{k})$ can be considered regarding their number, which in this case are represented by the check-in counters or self-service totem.

The M / G / k queues are more complex compared to the M / M / k queues, which requires a greater mathematical effort to determine the average time of the customer in the queue (WQ) and the average number of customers in the queue (LQ).

Ross (2007) developed the approach for calculating the average time in the system $\left(\mathrm{W}_{\mathrm{Q}}\right)$ in rows of the M / G / k type, as can be seen in Equation (6).

$$
W_{Q} \approx \frac{\lambda^{k} \mu D P^{k-1}}{2(k-1) !(k-\lambda D P)^{2}\left[\sum_{n=0}^{k-1} \frac{(\lambda D P)^{n}}{n !}+\frac{(\lambda D P)^{k}}{(k-1) !(k-\lambda D P)}\right]}
$$

Where: DP represents the standard deviation of service time $(\mu)$

The average number of customers in the queue (LQ) can be determined by the following relationship:

$$
L_{Q} \approx \lambda * W_{Q}
$$

\subsection{Design and evaluation of the operational components of a passenger terminal}

It is known that the dimensioning or verification of capacity and service level of airport components can be applied to three types of methods: (i) Empirical - ergonomic aspects are used based on the good sense and experience of the designers or researchers; (ii) Analytical - Use of equations, linear regressions, statistical data and Queuing Theory; (iii) Simulation - Creation of representative models and subsequent simulation with the aid of software (such as Arena and CAST Terminal, among others).

Table 3 presents a summary of the studies, presented in chronological order, which were the subject of this work. It is noted that some researchers used analytical methods while others used simulation. Some points in common with this work are highlighted: the use of Queuing Theory, operational component of the analyzed passenger terminal (check-in area), 
research methodology used to reduce scenarios (Taguchi Method) and type from case study airport

(regional).

The Taguchi Method for orthogonal array matrices is an important tool for reducing simulation scenarios, and has already been applied in academic studies in different areas. Borille and Correia (2013) used this tool to enable the simulation of landing procedures in large Brazilian airports.

Table 3 - Items covered, and methodologies adopted in the literature review studies

\begin{tabular}{|c|c|c|c|c|c|c|c|c|c|c|c|c|c|c|}
\hline & \multicolumn{14}{|c|}{ Research and year } \\
\hline Researched Itens & 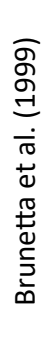 & 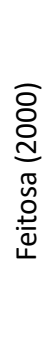 & 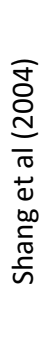 & 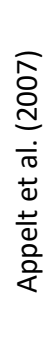 & 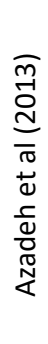 & 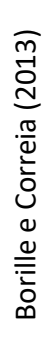 & 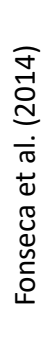 & 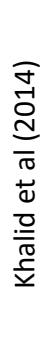 & 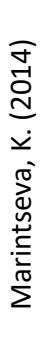 & 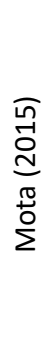 & 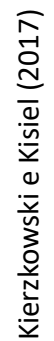 & 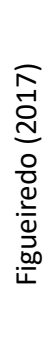 & 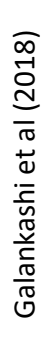 & 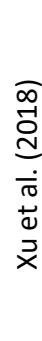 \\
\hline \multicolumn{15}{|l|}{ Queueing theory } \\
\hline \multicolumn{15}{|l|}{ check-in area } \\
\hline \multicolumn{15}{|l|}{ Taguchi method } \\
\hline Regional Airport & & & & & & & & & & & & & & \\
\hline
\end{tabular}

Queuing theory can also be used to solve problems in several areas where queuing is observed, such as banks, supermarkets, and toll plazas, among others. No studies have been found that apply the Taguchi techniques to reduce scenarios and further analyze through Queuing Theory and believe that the present work fills this gap by adding these techniques to the study of service level offered at check-in at regional airports.

\section{METHODOLOGY}

A summary of the methodology used and its steps is presented in Figure 1.

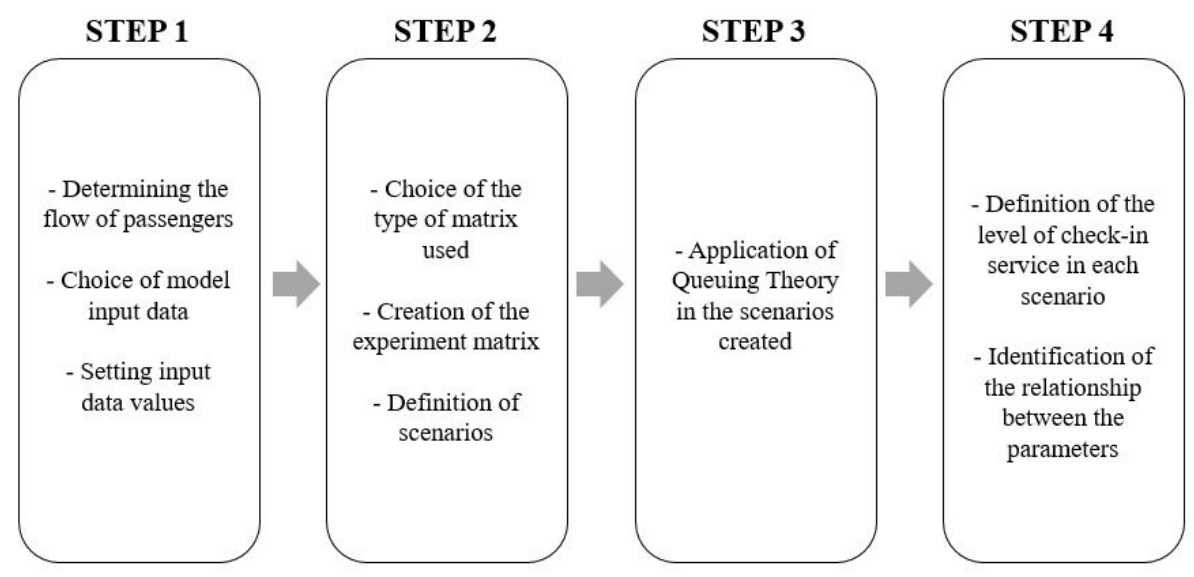

Figure 1. Steps of the proposed methodology 
The Queuing Theory is applied in the check-in area of the Modular Terminal M3, proposed by the Regional Aviation Development Program, which is the module with the highest capacity among the four presented by the program. The floor plan used as the basis for the model was provided by the Civil Aviation Secretariat.

In the design of this Modular Terminal M3 it is indicated that it will have a total of 3,550 $\mathrm{m}^{2}$ and boarding capacity for 200 passengers, of which approximately $208 \mathrm{~m}^{2}$ will be dedicated to the check-in procedure.

In a passenger terminal, the user can perform boarding, disembarking or connection procedures. Each of them uses certain operational components of the terminal, which must be capable of handling this movement. The design of the airport in study is of a regional type and, therefore, the procedures of passengers in connection were not considered. For this work, only the check-in area is considered, which is a step in the boarding flow

The flow sequence in the check-in area of this study follows the model found in most Brazilian airports. Figure 2 shows the scheme of possible flows for check-in procedures that passengers must follow, and the path taken by each user depends on the input data.

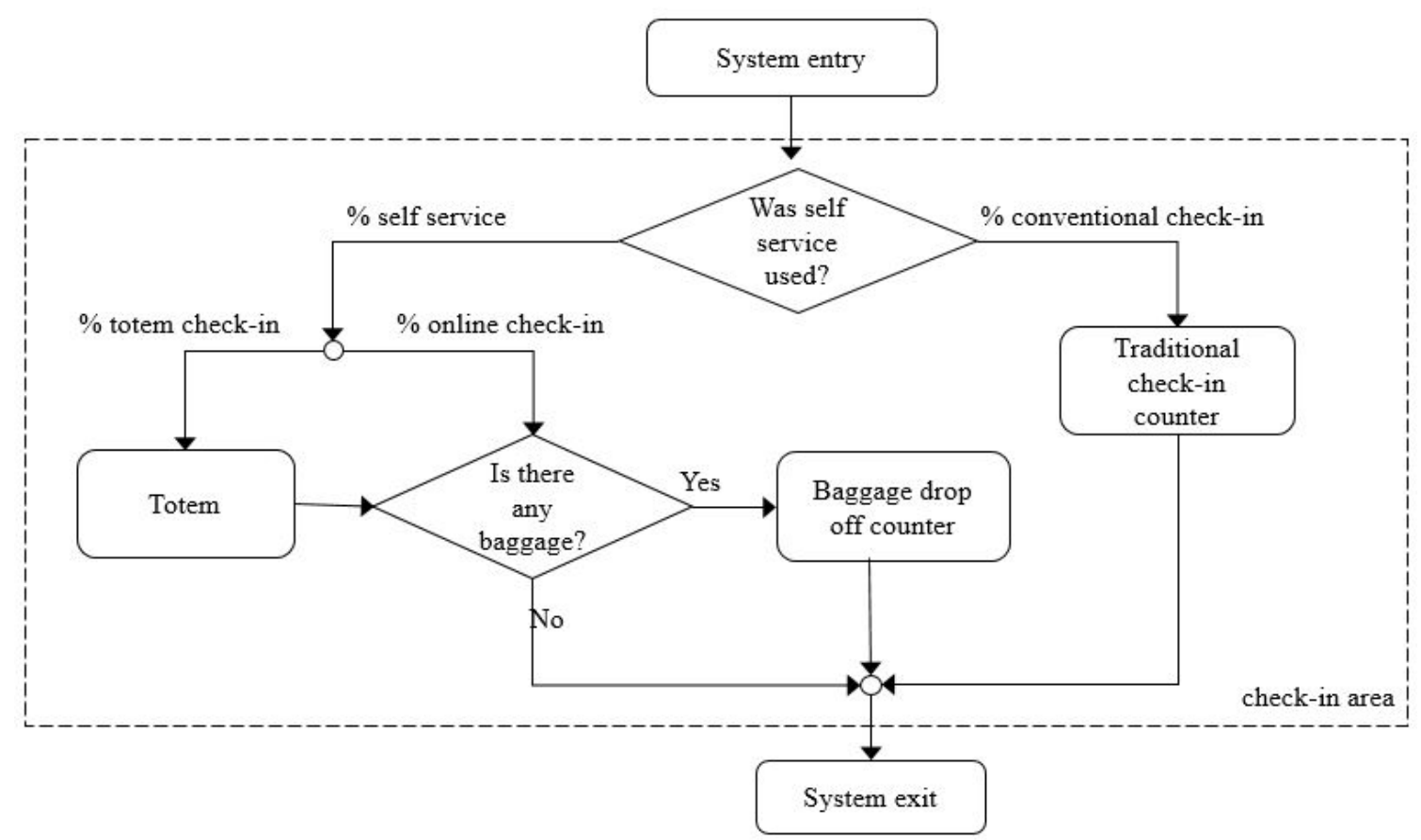

Figure 2. Possible flows for the check-in procedure

The flow of passengers in the check-in area of an airport terminal can be seen as a decision tree in which the user has options according to his profile, type of check-in and the need to check baggage. Therefore, different users can take different paths within the same system, which also affects their processing time.

\subsection{Model input data}

For the construction of the check-in model to be analyzed in this work, as well as for the application of queuing theory, possible scenarios are proposed for the check-in area. These scenarios are the result of a combination of factors (or parameters), creating several possibilities for operating the environment. 
As it is a passenger terminal that has not yet been built and that will be able to serve users of different profiles, some input data were stipulated in a manner consistent with that found in other regional airports in operation in Brazil.

The Taguchi Orthogonal Array Matrix is formed by factors and levels, and all factors must have the same number of levels. 10 factors were selected to represent the possibilities of events at the passenger terminal under study. The factors are: (a) Number of airlines operating, (b) Number of passengers processed, (c) Passenger arrival curve at the airport, (d) Usage fee for each type of check-in, (e) Distribution from the counters, (f) Fee for passengers with checked baggage, (g) Advance of opening the counters, (h) Service time at the traditional check-in counter, (i) Service time at the baggage drop-off counter, and (j) Service time at the self-service totem. For each of these factors, 4 levels were adopted, which are shown in Table 4.

Table 4 - Factors and levels adopted

\begin{tabular}{|c|c|c|c|c|c|c|c|c|c|}
\hline \multirow{2}{*}{ Factor } & \multirow{2}{*}{ Acronyms } & \multicolumn{8}{|c|}{ Level } \\
\hline & & \multicolumn{2}{|l|}{1} & \multicolumn{2}{|l|}{2} & \multicolumn{2}{|l|}{3} & \multicolumn{2}{|l|}{4} \\
\hline Number of passengers on board & Pax & \multicolumn{2}{|l|}{50} & \multicolumn{2}{|l|}{120} & \multicolumn{2}{|l|}{190} & \multicolumn{2}{|l|}{260} \\
\hline $\begin{array}{l}\text { Passenger arrival rate at the air- } \\
\text { port (\% of total in the } 30 \\
\text { minutes peak) }\end{array}$ & Tch & $20 \%$ & & $30 \%$ & & $40 \%$ & & $50 \%$ & \\
\hline \multirow{3}{*}{$\begin{array}{l}\text { Usage fee for each type of } \\
\text { check-in }\end{array}$} & \multirow{3}{*}{ Tut } & Counter & $20 \%$ & Counter & $30 \%$ & Counter & $40 \%$ & Counter & $50 \%$ \\
\hline & & Totem & $25 \%$ & Totem & $20 \%$ & Totem & $15 \%$ & Totem & $10 \%$ \\
\hline & & Online & $55 \%$ & Online & $50 \%$ & Online & $45 \%$ & Online & $40 \%$ \\
\hline $\begin{array}{l}\text { Passenger fee with checked } \\
\text { baggage }\end{array}$ & Tbg & \multicolumn{2}{|c|}{$30 \%$} & \multicolumn{2}{|l|}{$40 \%$} & \multicolumn{2}{|l|}{$50 \%$} & \multicolumn{2}{|l|}{$60 \%$} \\
\hline $\begin{array}{l}\text { Service time at the traditional } \\
\text { check-in desk }\end{array}$ & Tbt & \multicolumn{2}{|c|}{$02: 30$} & \multicolumn{2}{|l|}{ 03:00 } & \multicolumn{2}{|l|}{ 03:30 } & \multicolumn{2}{|l|}{ 04:00 } \\
\hline $\begin{array}{l}\text { Service time at the baggage } \\
\text { drop-off counter }\end{array}$ & Tbd & \multicolumn{2}{|c|}{ 01:30 } & \multicolumn{2}{|l|}{$01: 50$} & \multicolumn{2}{|l|}{$02: 10$} & \multicolumn{2}{|l|}{$02: 30$} \\
\hline Self-service totem service time & $\mathrm{Ttt}$ & \multicolumn{2}{|c|}{$02: 10$} & \multicolumn{2}{|l|}{$02: 30$} & \multicolumn{2}{|l|}{$02: 50$} & \multicolumn{2}{|l|}{ 03:10 } \\
\hline Number of traditional counters & $\mathrm{Bt}$ & \multicolumn{2}{|c|}{1} & \multicolumn{2}{|l|}{2} & \multicolumn{2}{|l|}{3} & \multicolumn{2}{|l|}{4} \\
\hline Number of self-service totems & $\mathrm{Ba}$ & \multicolumn{2}{|l|}{1} & \multicolumn{2}{|l|}{2} & \multicolumn{2}{|l|}{3} & \multicolumn{2}{|l|}{4} \\
\hline Number of dispatch counters & $\mathrm{Bd}$ & 1 & & 2 & & & & & \\
\hline
\end{tabular}

\section{APPLICATION OF THE METHODOLOGY AND ANALYSIS OF RESULTS}

\subsection{Creation of the experiment matrix}

The number of levels and factors adopted corresponds to a mixed level orthogonal array of the L'32 type ( $21 \times 49$ ), with 32 scenarios. The use of this technique reduced the number of necessary experiments from 13,122 to 32 scenarios, enabling the application of queuing theory. Table 5 shows the result of the combination, between 9 factors and 4 levels, and 1 factor and 2 levels, used to form the L32 matrix and the composition of each scenario.

\subsection{DETERMINATION OF THE QUANTITY OF EQUIPMENT REQUIRED}

In queuing theory, $\rho$ represents the percentage of time the system remains busy and measures system congestion. For queues with an exponential arrival pattern, the value of $\rho$ must be less than 1 to ensure that the passenger arrival rate is lower than the attendance rate. Otherwise, an infinite queue will be formed, making it impossible to calculate your performance measures. With the value of $\rho$, we can determine the amount of equipment or servers (traditional counter, dispatch counter and self-service totem) needed for the system to be stable. It is known that: 


$$
\rho=\frac{\lambda}{\mu k}
$$

For the system to be stable, $\rho<1$. Thus:

$$
k>\frac{\lambda}{\mu}
$$

In practice, when $\rho>1$, the system will not be able to process customers and the service level of the operational component will be considered suboptimal. This situation was verified in some of the scenarios and the relationship between the amount of equipment available and needed in each scenario is presented in the following topics.

\begin{tabular}{|c|c|c|c|c|c|c|c|c|c|c|}
\hline \multirow{2}{*}{ Scenario } & \multicolumn{10}{|c|}{ Ortogonal matrix L' ${ }^{\prime} 32$} \\
\hline & Bd & Pax & Tch & Tut & Tbg (\%) & Tbt & Tbd & $\mathrm{Ttt}$ & $\mathrm{Bt}$ & $\mathrm{Ba}$ \\
\hline 1 & 1 & 50 & $20 \%$ & $20-25-55$ & $30 \%$ & $02: 30$ & 01:30 & $02: 10$ & 1 & 1 \\
\hline 2 & 1 & 50 & $30 \%$ & $30-20-50$ & $40 \%$ & 03:00 & $01: 50$ & $02: 30$ & 2 & 2 \\
\hline 3 & 1 & 50 & $40 \%$ & $40-15-45$ & $50 \%$ & 03:30 & $02: 10$ & $02: 50$ & 3 & 3 \\
\hline 4 & 1 & 50 & $50 \%$ & $50-10-40$ & $60 \%$ & 04:00 & $02: 30$ & 03:10 & 4 & 4 \\
\hline 5 & 1 & 120 & $20 \%$ & $20-25-55$ & $40 \%$ & 03:00 & $02: 30$ & $02: 50$ & 4 & 4 \\
\hline 6 & 1 & 120 & $30 \%$ & $30-20-50$ & $30 \%$ & $02: 30$ & $02: 10$ & 03:10 & 3 & 3 \\
\hline 7 & 1 & 120 & $40 \%$ & $40-15-45$ & $60 \%$ & $04: 00$ & $01: 50$ & $02: 10$ & 2 & 2 \\
\hline 8 & 1 & 120 & $50 \%$ & $50-10-40$ & $50 \%$ & 03:30 & $01: 30$ & $02: 30$ & 1 & 1 \\
\hline 9 & 1 & 190 & $20 \%$ & $30-20-50$ & $50 \%$ & 04:00 & 01:30 & $02: 30$ & 3 & 4 \\
\hline 10 & 1 & 190 & $30 \%$ & $20-25-55$ & $60 \%$ & 03:30 & 01:50 & $02: 10$ & 4 & 3 \\
\hline 11 & 1 & 190 & $40 \%$ & $50-10-40$ & $30 \%$ & 03:00 & 02:10 & 03:10 & 1 & 2 \\
\hline 12 & 1 & 190 & $50 \%$ & $40-15-45$ & $40 \%$ & $02: 30$ & $02: 30$ & $02: 50$ & 2 & 1 \\
\hline 13 & 1 & 260 & $20 \%$ & $30-20-50$ & $60 \%$ & 03:30 & $02: 10$ & 03:10 & 2 & 1 \\
\hline 14 & 1 & 260 & $30 \%$ & $20-25-55$ & $50 \%$ & 04:00 & $02: 30$ & $02: 50$ & 1 & 2 \\
\hline 15 & 1 & 260 & $40 \%$ & $50-10-40$ & $40 \%$ & $02: 30$ & 01:30 & $02: 30$ & 4 & 3 \\
\hline 16 & 1 & 260 & $50 \%$ & $40-15-45$ & $30 \%$ & $03: 00$ & $01: 50$ & $02: 10$ & 3 & 4 \\
\hline 17 & 2 & 50 & $20 \%$ & $50-10-40$ & $30 \%$ & 04:00 & $01: 50$ & $02: 50$ & 2 & 3 \\
\hline 18 & 2 & 50 & $30 \%$ & $40-15-45$ & $40 \%$ & $03: 30$ & $01: 30$ & $03: 10$ & 1 & 4 \\
\hline 19 & 2 & 50 & $40 \%$ & $30-20-50$ & $50 \%$ & 03:00 & $02: 30$ & $02: 10$ & 4 & 1 \\
\hline 20 & 2 & 50 & $50 \%$ & $20-25-55$ & $60 \%$ & $02: 30$ & $02: 10$ & $02: 30$ & 3 & 2 \\
\hline 21 & 2 & 120 & $20 \%$ & $50-10-40$ & $40 \%$ & 03:30 & $02: 30$ & $02: 10$ & 3 & 2 \\
\hline 22 & 2 & 120 & $30 \%$ & $40-15-45$ & $30 \%$ & $04: 00$ & $02: 10$ & $02: 30$ & 4 & 1 \\
\hline 23 & 2 & 120 & $40 \%$ & $30-20-50$ & $60 \%$ & $02: 30$ & 01:50 & $02: 50$ & 1 & 4 \\
\hline 24 & 2 & 120 & $50 \%$ & $20-25-55$ & $50 \%$ & 03:00 & $01: 30$ & $03: 10$ & 2 & 3 \\
\hline 25 & 2 & 190 & $20 \%$ & $40-15-45$ & $50 \%$ & $02: 30$ & $01: 50$ & $03: 10$ & 4 & 2 \\
\hline 26 & 2 & 190 & $30 \%$ & $50-10-40$ & $60 \%$ & 03:00 & $01: 30$ & $02: 50$ & 3 & 1 \\
\hline 27 & 2 & 190 & $40 \%$ & $20-25-55$ & $30 \%$ & 03:30 & $02: 30$ & $02: 30$ & 2 & 4 \\
\hline 28 & 2 & 190 & $50 \%$ & $30-20-50$ & $40 \%$ & 04:00 & $02: 10$ & $02: 10$ & 1 & 3 \\
\hline 29 & 2 & 260 & $20 \%$ & $40-15-45$ & $60 \%$ & 03:00 & $02: 30$ & $02: 30$ & 1 & 3 \\
\hline 30 & 2 & 260 & $30 \%$ & $50-10-40$ & $50 \%$ & $02: 30$ & $02: 10$ & $02: 10$ & 2 & 4 \\
\hline 31 & 2 & 260 & $40 \%$ & $20-25-55$ & $40 \%$ & $04: 00$ & $01: 50$ & $03: 10$ & 3 & 1 \\
\hline 32 & 2 & 260 & $50 \%$ & $30-20-50$ & $30 \%$ & 03:30 & 01:30 & $02: 50$ & 4 & 2 \\
\hline
\end{tabular}

Table 5 - Experiment Matrix (Scenarios) $L^{\prime} 32$.

\subsubsection{Traditional counters}

The number of traditional check-in counters was insufficient in 12 of the 32 proposed scenarios. Figure 3 shows the relationship between the number of counters available and necessary in each of the hypotheses of the study. The dashed line represents the $\rho$, that is, the scenarios represented by dots to its right (red) have $\rho>1$ and, therefore, are unstable. 
In 10 of the 12 scenarios with $\rho>1$ (represented in Figure 3 by the numbers: 8, 11, 12, 14, $15,16,28,29,30$ and 32), the number of passengers processed was 190 or 260 passengers, proving the logic that a greater volume of customers will demand more service equipment from the system.

Other scenarios with the same number of users showed $\rho<1$ due to the influence of other factors such as: (i) low rate of use of the traditional check-in counter, (ii) fast processing of customers, and (iii) number of counters compatible with the volume of passengers.

This is the case of scenario 31, in which 3 traditional counters were sufficient to process 260 users. In this case, only $20 \%$ of the total passengers used the equipment.

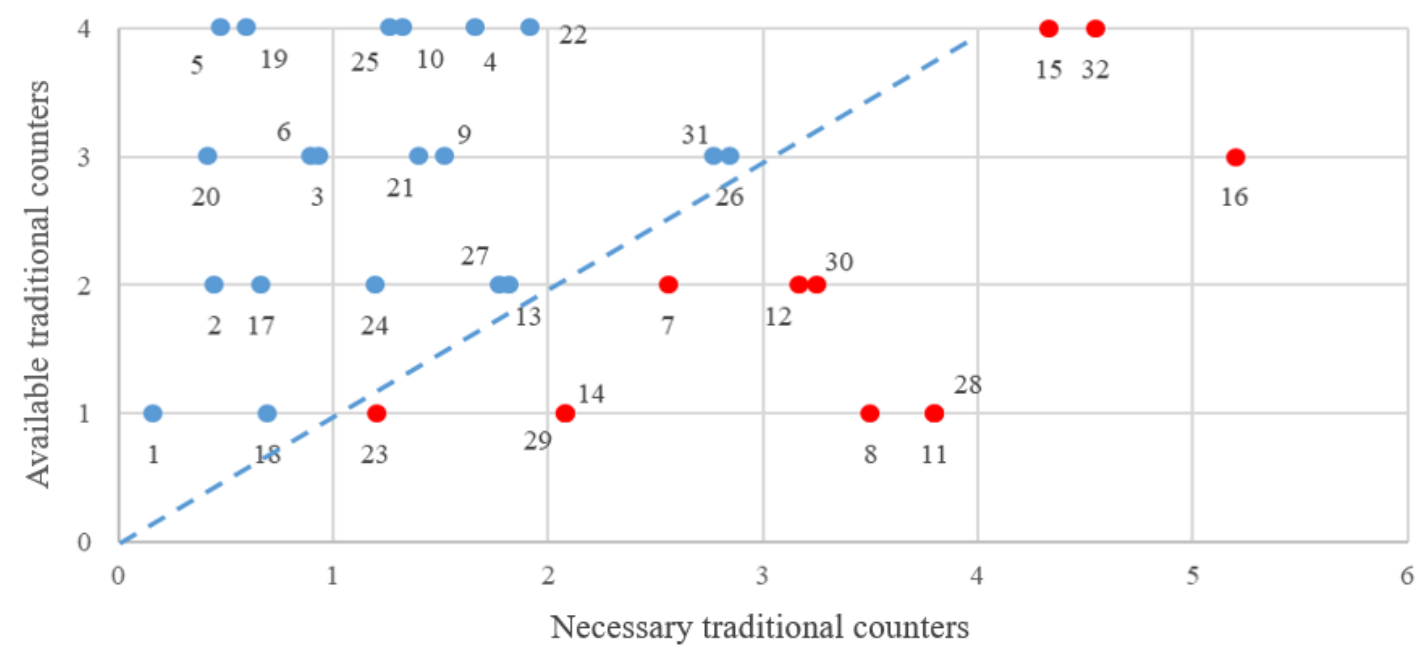

Figure 3. Relationship between the number of available and necessary traditional counters

On the other hand, the service was underused in some scenarios such as "experiment 19", for example, in which 4 traditional check-in counters were offered for processing only 50 passengers, of which only $40 \%$ used the equipment. In cases like these, queuing theory can be an important tool for system optimization and cost reduction, as the demand for this scenario would be met with just one counter.

\subsubsection{Baggage drop-off counters}

For the analysis of the number of baggage drop-off counters, this study considers scenarios with 1 or 2 units and among the 32 analysis scenarios, it is found that in 11 experiments the number of check-in counters is insufficient. The equipment is used by passengers who have checked in online or by the self-service totem and have luggage to be dropped off. In this case, the percentage of users with luggage becomes a determining factor, but the type of check-in and the number of passengers processed are also relevant.

The relationship between the number of exclusive counters for the dispatch of available luggage ( $\mathrm{Y}$ axis) and the required quantity (X axis) is shown in Figure 4 and the dashed line represents the $\rho$, that is, the scenarios represented by points on your right (red) have $\rho>1$, therefore, they are unstable.

Among the study scenarios, all of them would be served with at least 3 baggage drop-off counters, except scenarios 14 and 31, which require 4 pieces of equipment. 
Both have high levels for the factors that are highlighted below:

- 260 passengers processed;

- $80 \%$ of passengers checked in online or on the self-service totem; and

- $60 \%$ of passengers must check baggage.

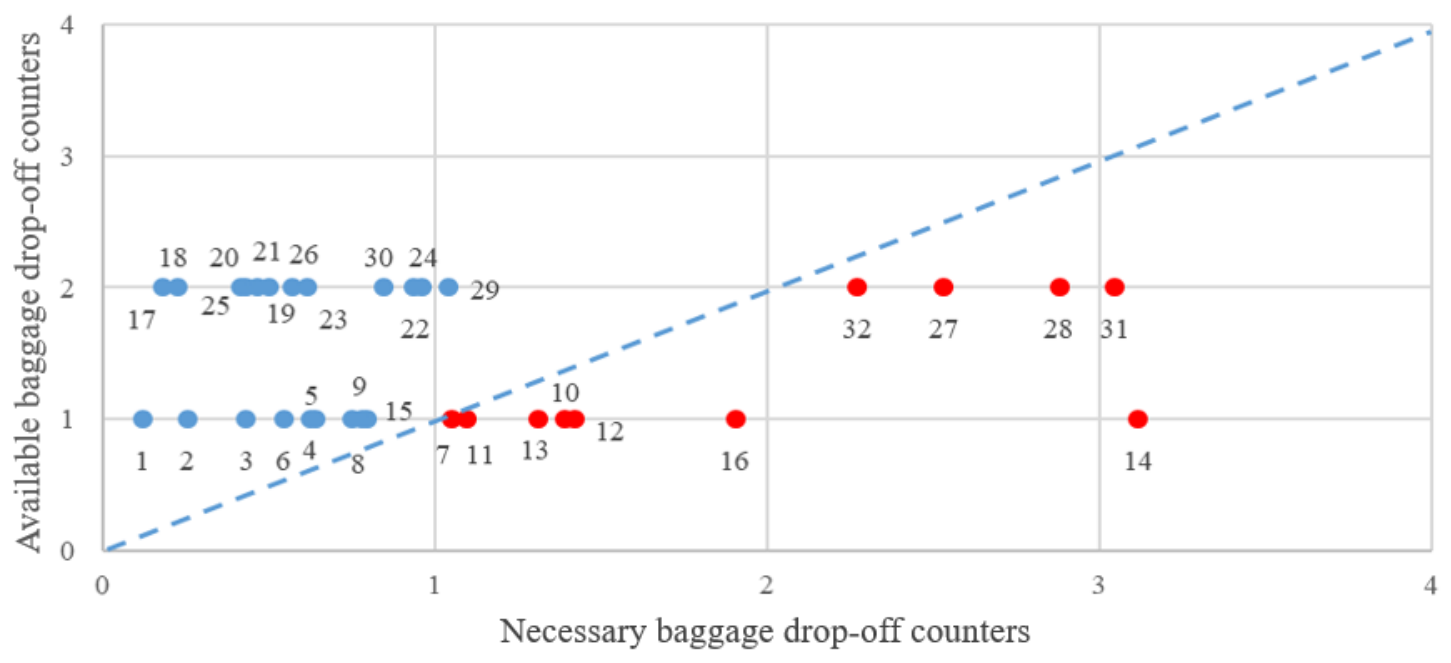

Figure 4. Relationship between the number of available and necessary baggage drop-off counters

\subsubsection{Self-service totem}

Scenarios are also proposed in which the number of self-service totems varies between 1 and 4. The relationship between the number of available totems (Y axis) and necessary ones (X axis) in each of the hypotheses of the study is shown in Figure 5, in which the dashed line represents the $\rho$, and the experiments represented by points on the right have $\rho>1$ and, therefore, are unstable.

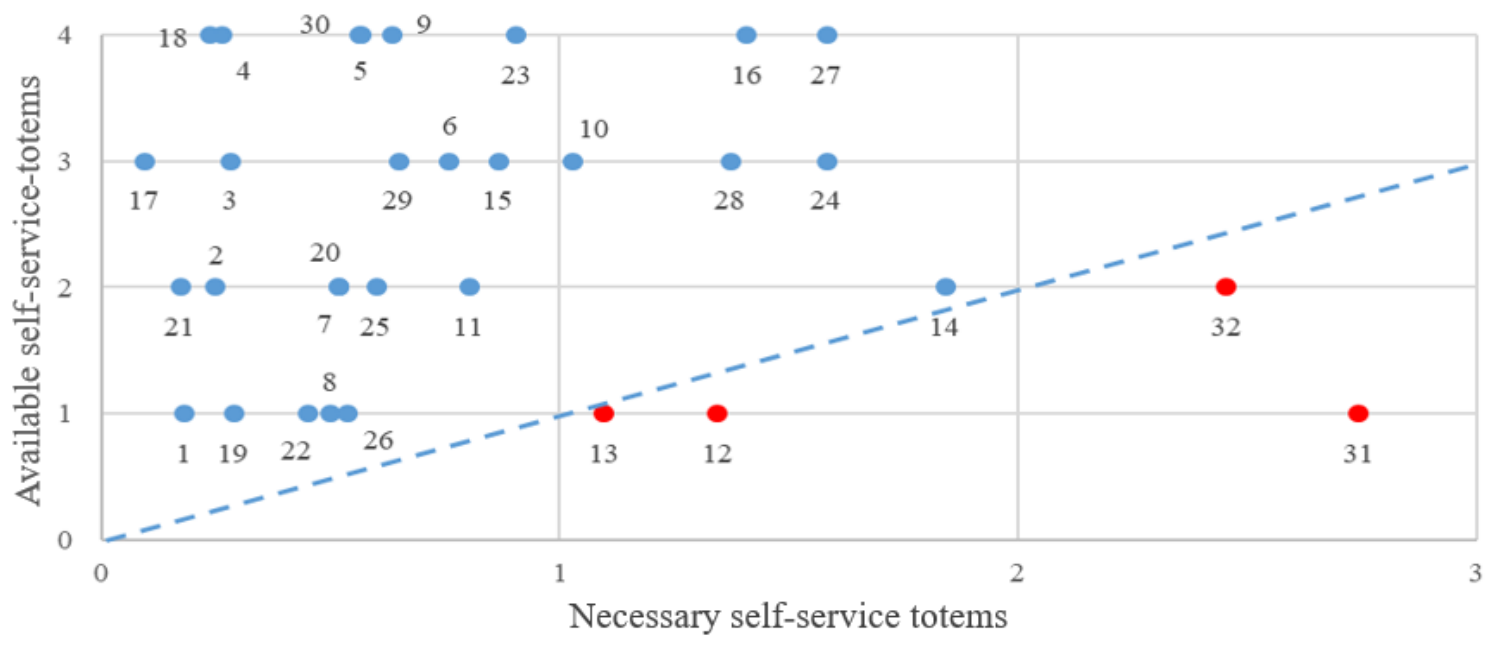

Figure 5. Relationship between the number of available and necessary self-service totems

In 28 of the 32 scenarios in the study, the number of self-service totems is sufficient to process passengers $(\rho<1)$ and only 1 totem would be necessary to guarantee system stability in 
$68.75 \%$ of the scenarios. The number of equipment proposed for the traditional check-in counters and self-service totems was the same (ranging from 1 to 4 units), but this amount proved to be sufficient for more scenarios in relation to the self-service totems. This observation was already expected since totems have a shorter service time and usage rate than traditional counters.

\subsection{Service level assessment}

To determine the service level of the check-in area, it is necessary to know the processing times and the area available to each passenger during the peak movement of the terminal. Thus, the queuing theory was applied to the 32 analysis scenarios, then, the values of the approximate average time of the customer in the queue $\left(\mathrm{W}_{\mathrm{Q}}\right)$ and the approximate average of customers in the system (L) are obtained.

The average time of the customer in the queue $\left(\mathrm{W}_{\mathrm{Q}}\right)$ was the parameter to determine the level of service in each type of check-in (traditional counter, drop off counter and self-service totem) in relation to the user's waiting time. Each type has different classifications for the level of service, and the same was evaluated for each case.

Table 6 - Service level pattern for the 32 scenarios analyzed

\begin{tabular}{|c|c|c|c|c|c|c|c|c|c|c|}
\hline \multirow{3}{*}{ 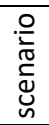 } & \multicolumn{5}{|c|}{ Queue with M / M / k behavior } & \multicolumn{5}{|c|}{ Queue with M / G / k behavior } \\
\hline & \multicolumn{3}{|c|}{ Processing time } & \multirow{2}{*}{ Area } & \multirow{2}{*}{ General } & \multicolumn{3}{|c|}{ Processing time } & \multirow{2}{*}{ Area } & \multirow{2}{*}{ General } \\
\hline & Trad. & Totem & Desp. & & & Trad. & Totem & Desp. & & \\
\hline 1 & Over. & Optimal & Optimal & Over. & Optimal & Over. & Over. & Over. & Over. & Over. \\
\hline 2 & Over. & Optimal & Optimal & Over. & Optimal & Over. & Over. & Over. & Over. & Over. \\
\hline 3 & Over. & Over. & Optimal & Over. & Optimal & Over. & Over. & Over. & Over. & Over. \\
\hline 4 & Over. & Over. & Optimal & Over. & Optimal & Over. & Over. & Optimal & Over. & Optimal \\
\hline 5 & Over. & Over. & Optimal & Over. & Optimal & Over. & Over. & Optimal & Over. & Optimal \\
\hline 6 & Over. & Over. & Optimal & Over. & Optimal & Over. & Over. & Optimal & Over. & Optimal \\
\hline 7 & Sub. & Optimal & Sub. & Sub. & Sub. & Sub. & Over. & Sub. & Sub. & Sub. \\
\hline 8 & Sub. & Sub. & Optimal & Sub. & Sub. & Sub. & Optimal & Optimal & Sub. & Sub. \\
\hline 9 & Over. & Over. & Sub. & Over. & Sub. & Over. & Over. & Optimal & Over. & Optimal \\
\hline 10 & Over. & Optimal & Sub. & Sub. & Sub. & Over. & Over. & Sub. & Sub. & Sub. \\
\hline 11 & Sub. & Optimal & Sub. & Sub. & Sub. & Sub. & Over. & Sub. & Sub. & Sub. \\
\hline 12 & Sub. & Sub. & Sub. & Sub. & Sub. & Sub. & Sub. & Sub. & Sub. & Sub. \\
\hline 13 & Optimal & Sub. & Sub. & Sub. & Sub. & Over. & Sub. & Sub. & Sub. & Sub. \\
\hline 14 & Sub. & Sub. & Sub. & Sub. & Sub. & Sub. & Optimal & Sub. & Sub. & Sub. \\
\hline 15 & Sub. & Over. & Sub. & Sub. & Sub. & Sub. & Over. & Optimal & Sub. & Sub. \\
\hline 16 & Sub. & Over. & Sub. & Sub. & Sub. & Sub. & Over. & Sub. & Sub. & Sub. \\
\hline 17 & Over. & Over. & Over. & Over. & Over. & Over. & Over. & Over. & Over. & Over. \\
\hline 18 & Over. & Over. & Over. & Over. & Over. & Over. & Over. & Over. & Over. & Over. \\
\hline 19 & Over. & Optimal & Optimal & Over. & Optimal & Over. & Over. & Over. & Over. & Over. \\
\hline 20 & Over. & Optimal & Optimal & Over. & Optimal & Over. & Over. & Over. & Over. & Over. \\
\hline 21 & Over. & Over. & Optimal & Over. & Optimal & Over. & Over. & Over. & Over. & Over. \\
\hline 22 & Over. & Sub. & Optimal & Over. & Sub. & Over. & Over. & Over. & Over. & Over. \\
\hline 23 & Sub. & Over. & Optimal & Sub. & Sub. & Sub. & Over. & Over. & Sub. & Sub. \\
\hline 24 & Over. & Optimal & Optimal & Over. & Optimal & Over. & Over. & Over. & Over. & Over. \\
\hline 25 & Over. & Optimal & Over. & Over. & Optimal & Over. & Over. & Over. & Over. & Over. \\
\hline 26 & Sub. & Sub. & Optimal & Over. & Sub. & Over. & Optimal & Over. & Over. & Optimal \\
\hline 27 & Optimal & Over. & Sub. & Sub. & Sub. & Over. & Over. & Sub. & Sub. & Sub. \\
\hline 28 & Sub. & Optimal & Sub. & Sub. & Sub. & Sub. & Over. & Sub. & Sub. & Sub. \\
\hline 29 & Sub. & Over. & Optimal & Sub. & Sub. & Sub. & Over. & Over. & Sub. & Sub. \\
\hline 30 & Sub. & Over. & Optimal & Sub. & Sub. & Sub. & Over. & Over. & Sub. & Sub. \\
\hline 31 & Optimal & Sub. & Sub. & Sub. & Sub. & Over. & Sub. & Sub. & Sub. & Sub. \\
\hline 32 & Sub. & Sub. & Sub. & Sub. & Sub. & Sub. & Sub. & Sub. & Sub. & Sub. \\
\hline
\end{tabular}


Regarding the level of service related to the space available to each user of the system, the value is obtained by dividing the area allocated to check-in by the number of customers in the system during the most congested period. As it is a unique environment and the classification of the service level is the same for all types of check-in, the number of passengers is considered as the sum of users of the traditional counter, dispatch counter and self-service totem.

In addition, the worst level of performance across time and space is considered as the overall service level in each scenario. Table 4.3 shows the service level obtained by the queuing theory for each scenario considering the model as M / M / k and M / G / k. In Table 6, the green color represents the oversized service level, the yellow color represents the optimal standard and the red color the suboptimal standard.

The service time for queues of $\mathrm{M} / \mathrm{M} / \mathrm{k}$ type follows an exponential rate, that is, it can vary more in relation to queues of type M / G / k. This flexibility directly interfered with the result of each type of check-in, and the service levels obtained by the $\mathrm{M} / \mathrm{M} / \mathrm{k}$ lines are lower compared to the models using the M / G / $\mathrm{k}$ type.

The time of attendance at check-in counters and totems can vary in some situations depending on the occurrence of unforeseen circumstances or lack of practice by the attendant, for example. Frequent passengers tend to check-in in considerably less time compared to a user who will be performing the procedure for the first time. Difficulties in using technology such as selfservice totems, for example, also interfere with the final processing time. In this context, the $\mathrm{M} / \mathrm{M} / \mathrm{k}$ queues consider this variation and the results obtained for the service level were satisfactory.

On the other hand, in lines of type M / G / k, the service time is not exponential and varies within a standard deviation, which was considered as 0.5 minutes for this model.

The low fluctuation in the average service time $(\mu)$ made the estimated average customer time in queue $\left(\mathrm{W}_{\mathrm{Q}}\right)$ values low and the service level oversized in almost all scenarios.

The sub-optimal service levels found were the result of system instability caused by $\rho>1$.

\section{CONCLUSIONS}

In this study, different methods were used to assess the service level of the check-in area of a Brazilian regional airport model. Considering that each user has a certain profile and several possibilities to perform this procedure, the possible paths of passengers were mapped to understand their possible behavior within the studied area.

The Taguchi Orthogonal Matrix Method was used to reduce these possibilities and create possible scenarios to be analyzed. After this stage, factors and levels that interfere with the passenger flow at the terminal were determined. With this method it was possible to establish parameters according to data from existing Brazilian airports and generate coherent results even without the need for further research or data collection.

Queuing Theory was the method used to analyze the 32 scenarios created and determine the corresponding service level for each one according to the average waiting time and the available area for each passenger.

The main parameters that helped to describe the queue behavior were determined through equations

The queues were analyzed considering the M / M / k and M / G / k models, and the results of the first were coherent, considering that the average service time can vary considerably 
according to the profile of the customer and the employee responsible for performing the procedure. The M / M / k model is also widely used in academic studies and some examples of its use have been pointed out in the literature review.

The passenger terminal in the case study (Module M3) has a declared capacity of 200 passengers, but in some scenarios, the service level was considered suboptimal for processing lower numbers of users than this one. However, the terminal has an area suitable for the declared passenger capacity and the addition of check-in counters and self-service totems can solve this problem. In addition, in some scenarios, several counters less than that indicated by the project were considered.

The study also provided parameters that can be used to design new airport passenger terminals or to optimize areas in operation. Easy-to-understand graphs can be used to determine the required number of check-in counters, baggage drop-offs and self-service totems according to the number of passengers processed. The proposed model is easy to apply and provides an analytical solution for the analysis of the check-in procedure. In this context, simulation is also an excellent tool for this investigation, but the high cost of software and the lack of trained labor makes it difficult to apply, especially in small airports.

\section{ACKNOWLEDGEMENTS}

The authors are grateful for the support offered by CAPES - Coordination for the Improvement of Higher Education Personnel.

\section{REFERENCES}

Abd, Khalid; Abhary, Kazem; Marian, Romeo (2014) Simulation modelling and analysis of scheduling in robotic flexible assembly cells using Taguchi method. International Journal of Production Research, v. 52, p. 2654-2666. DOI: 10.1080/00207543.2013.867082.

Agência Nacional De Aviação Civil (2017) Anuário do Transporte Aéreo 2016, volume único, 1a edição. Brasília.

Andreatta, Giovanni; Brunetta, Lorenzo; Righi, Lucca (2007) Evaluating terminal management performances using SLAM: the case of Athens International Airport. Computers \& Operations Research, v. 34, n. 6, p. 1532-1550. DOI: 10.1016/j.cor.2005.07.024.

APPELT, Simone et el. (2007) Simulation of passenger check-in at a medium-sized US airport. In: Winter Simulation Conference 2017, Washington, DC. Piscataway: IEEE, 2007. P. 1252-1260. DOI: 10.1109/WSC.2007.4419729.

Arenales, M.; Armentano, V.; Morabito, R.; Yanasse, H (2007) Pesquisa Operacional para cursos de Engenharia. Rio de Janeiro. Elsevier.

Azadeh, A.; Sheikhalishahi, M.; Firoozi, M.; Khalili, S.M. (2013) An integrated multi-criteria Taguchi computer simulation-DEA approach for optimum maintenance policy and planning by incorporating learning effects. International Journal of Production Research, v. 51, p. 5374-5385. DOI: 10.1080/00207543.2013.774496.

Borille, Giovanna Miceli Ronzani; Correia, Anderson Ribeiro (2013) A method for evaluating the level of service arrival componentes at airports. Journal of Air Transport Management, v. 27, p. 5-10, 2013. DOI: 10.1016/j.jairtraman.2012.10.008.

Chwif, L.; Medina, A. C. (2014) Modelagem e Simulação de Eventos Discretos: Teoria e Aplicações. São Paulo. Elsevier.

Feitosa, M. V. M. (2000) Um modelo de simulação para terminais de passageiros em aeroportos regionais brasileiros. 141p. Dissertação (Mestrado em Engenharia de Infraestrutura Aeronáutica) - Instituto Tecnológico de Aeronáutica. São José dos Campos. Brasil.

Figueiredo, Luiz Antonio (2017) Simulação do processamento de passageiros: Check point do terminal aeroportuário de Goiânia. Dissertação (Mestrado em Engenharia de Produção e Sistemas) - Pontifícia Universidade Católica de Goiás, Goiânia.

Fogliatti, M. C.; Mattos, N. M. C. (2007) Teoria de Filas. Rio de Janeiro. Editora Interciência.

Galankashi, Masoud Rahiminezhad; Fallahiarezoudar, Ehsan; Moazzami, Anoosh; Helmi, Syed Ahmad; Rohani, Jafri Mohd; Yusof, Noordin Mohd (2018) An efficient integrated simulation-Taguchi approach for sales rate evaluation of a petrol station. Neural Computing \& Applications; v. 29; p. 1073-1085. DOI: 10.1007/s00521-016-2491-5.

International Air Transport Association. IATA (2019) Airport Development Reference Manual. 11th Ed. Montreal.

Kierzkowski, Artur; Kisiel, Tomasz 2017) Simulation model of security system functioning: A case study of the Wroclaw Airport terminal. Journal of Air Transport Management, v. 64, p. 173-185. DOI: 10.1016/j.jairtraman.2016.09.008.

Mckinsey \& Company (2010) Estudo do setor de transporte aéreo do Brasil: relatório consolidado. Rio de Janeiro.

Mota, Miguel Mujica (2015) Check-in allocation improvements through the use of a simulation-optimization approach. Transportation Research Part A, v.77, p. 320-335. DOI: 10.1016/j.tra.2015.04.016.

Oliveira, A. V. M.; Silva, L. H. S (2008) Constituição do marco regulatório para o mercado brasileiro de aviação regional. Brasília: Ministério do Turismo. 
P. Fonseca I Casas; J. Casanovas; X. Ferran (2014) Passenger flow simulation in a hub airport: an application to the Barcelona International Airport. Simulation Modelling Practice and Theory, v. 44, p. 78-94. D0I: 10.1016/j.simpat.2014.03.008.

Rolim, Paula Sutherland Wallauer (2016) Metodologia de Avaliação de Fatores Determinantes no Nível de Serviço Oferecido no Check-in de Voos Internacionais. 99f. Dissertação de mestrado em Engenharia de Infraestrutura Aeronáutica, Área de Transporte Aéreo e Aeroportos - Instituto Tecnológico de Aeronáutica, São José dos Campos.

Ross, P. J (1991) Aplicações das técnicas de Teguchi na engenharia de qualidade. Rio de Janeiro. Macron Books.

Ross, S. M (2007) Introduction to Probability Models. Ninth Edition. San Diego. Elsevier.

Secretaria De Aviação Civil. SAC (2017) Aviação Regional: Conectando o Brasil. Disponível em <http://www.aviacao.gov.br/noticias/2015/01/programa-de-desenvolvimento-aviacao-regional-quer-democratizar-o-transporte-aereono-brasil-1/aviacao-regional-versao-site-v4-final.pdf>. Accessed August 20, 2017.

Shang, Jen S.; Shanling Li; Tadikamalla, Pandu (2004) Operational design of a supply chain system using the Taguchi method, response surface methodology, simulation, and optimization. International Journal of Production Research., v. 42, p. 38233849. DOI: $10.1080 / 00207540410001704050$. 